Bull. Chem. Soc. Ethiop. 2021, 35(1), 87-96.

(C) 2021 Chemical Society of Ethiopia and The Authors

ISSN 1011-3924

DOI: https://dx.doi.org/10.4314/bcse.v35i1.7

Printed in Ethiopia

Online ISSN 1726-801X

\title{
BIOACTIVITIES OF HOLMIUM(III) AND GADOLINIUM(III) COMPLEXES OF THYMOQUINONE
}

Nasser S. Awwad ${ }^{1,2}$, Hala A. Ibrahium ${ }^{3,4}$, Ali A. Shati ${ }^{3}$, Mohammed A. Alshehri ${ }^{3}$, Khalid M. AlSyaad $^{3}$, Mohammad Y. Alfaifi ${ }^{3}$, Mohammad I. Mujallid ${ }^{5}$, Mutasem Z. Bani-Fwaz ${ }^{2}$, Hisham S. M. Abd-Rabboh ${ }^{2}$, Yi-Hsu Ju ${ }^{6}$ and Ahmed E. Fazary ${ }^{7,8^{*}}$

${ }^{1}$ Research Center for Advanced Materials Science (RCAMS), King Khalid University, P.O. Box 9004, Abha 61413, Saudi Arabia

${ }^{2}$ Chemistry Department, Faculty of Science, King Khalid University, Abha 9004, Abha 61413, Saudi Arabia

${ }^{3}$ Department of Biology, Faculty of Science, King Khalid University, Abha 9004, Abha 61413, Saudi Arabia

${ }^{4}$ Department of Semi Pilot Plant, Nuclear Materials Authority, P.O. Box 530, El Maadi, Egypt

${ }^{5}$ Department of Biological Sciences, Faculty of Science, King Abdul Aziz University, Jeddah, Saudi Arabia

${ }^{6}$ Graduate Institute of Applied Science and Technology, Department of Chemical Engineering, Taiwan Building Technology Center, National Taiwan University of Science and Technology, 43 Section 4, Keelung Road, Taipei 10607, Taiwan

${ }^{7}$ Applied Research Department, Research and Development Sector, Egyptian Organization for Biological Products and Vaccines (VACSERA Holding Company), 51 Wezaret El-Zeraa St., Agouza, Giza, Egypt

${ }^{8}$ National Committee for Pure and Applied Chemistry (NCPAC 2018-2022), Academy of Scientific Research and Technology (ASRT), 110 Al Kasr Al Aini, El-Sayeda Zainab, Cairo Governorate 11334, Egypt

(Received June 20, 2020; Revised February 28, 2021; Accepted March 10, 2021)

\begin{abstract}
Chemotherapeutic agents which are the main stay in cancer treatment are toxic with numerous contrary side effects. A number of chemical, physical, and computational techniques were applied to synthesize and elucidate the structural and functional characterization of the new designed bioligands and their metal complexes. Besides, several biological techniques for developing therapeutics and diagnostics agents of these new designed materials were used. The trivalent holmium(III) and gadolinium(III) metal complexes of thymoquinone (TQ) were synthesized. Toxicities and other bioactivites were undertaken with existing drug combinations and more effective tumor models will be established. The molecular structures of TQ-metal complexes were elucidated based on particular spectral approaches. The NF-kB (nuclear factor kappa-light-chain enhancer of activated B Cells) luciferase, elastase release, superoxide anion $\left(\mathrm{O}_{2}{ }^{\bullet}\right)$ generation, and DPPH (1,1-diphenyl-2picryl hydrazyl) free-radical scavenging activities of TQ and its synthesized complexes were elucidated and discussed. The core research is to use coordination and organometallic chemistry to design new bioligands and binary, ternary, mixed ligand, multi metal multi ligand complexes pursing a bio target continuously with structureactivity relationships (SARS).
\end{abstract}

KEY WORDS: Thymoquinone, Holmium, Gadolinium, Bioactivities

\section{INTRODUCTION}

At the present time, there is a tendency in searching for anticancer substances in the natural sources. These natural sources are usually supposed to be fewer toxic effects and produce negligible side effects $[1,2]$. Medications from ordinary sources have been used conventionally

*Corresponding author. E-mail: aefazary@gmail.com

This work is licensed under the Creative Commons Attribution 4.0 International License 
for thousands of ages in manyplaces of the world [3]. Experts have embattled numerous traditional or common drugs in similar of contemporary medicine to recognize and extract vigorous ingredients for the medication development [4]. Thymoquinone (2-methyl-5-isopropyl1,4-benzoquinone, Scheme 1), a monoterpene molecule is a most prominent constituent phytochemical compound found in black cumin (Nigella sativa) with a long history of medicinal use [5]. Clinical studies with thymoquinone (TQ, Scheme 1) in humans had showed its general safety even up to a dose of $10 \mathrm{mg} / \mathrm{kg} /$ day with individual few side possessions [6-10].
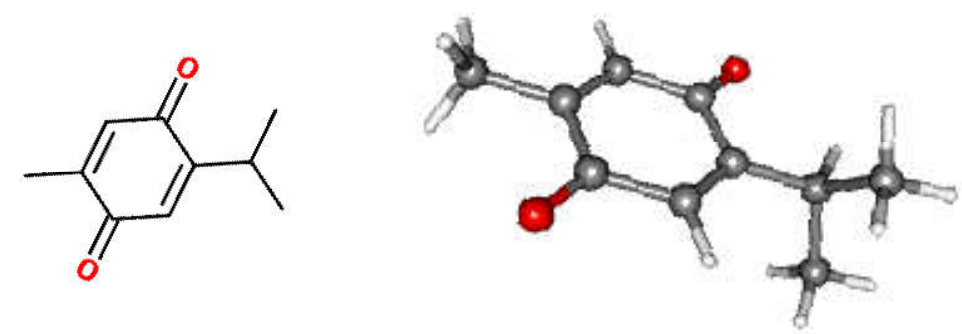

Scheme 1. Molecular structure of TQ and its computer-generated model.

The problem met in clinical trials concerning TQ is its poor bioavailability, leading to little levels in plasma and tissue as shown in most pharmacokinetics research work done in TQ bioligand [11-22]. As well, it's hydrophobic in nature, rapidly eliminated and slowly/poorly absorbed. However, exploring other mechanism to improve the bioavailability of TQ especially chemical modelling may prove as a novel method [11-22]. Furthermore, great lipophilicity of TQ makes poor formulation features. Numerous investigational studies have been done to avoid the pharmacokinetic difficulties of thymoquinone [23-25], and its contrary effect. An extremely promising and advanced approach to deal with the bioavailability matter and to realize even extra various potential health benefits is the usage of metal ion-TQ complex, forming a binary complex formation. Both holmium and gadolinium metals play no known biological role in biological processes, however, their salts and chelates were found to be able to stimulate metabolism in humans. Holmium and gadolinium forms trivalent ions occurring in watersoluble salts with fluorescent properties and toxic to mammals [26, 27]. Though, homium(III) and gadolinium(III) chelates are far less toxic because they carry metal ions over the kidneys and out of the body before the free ion can be released into the body tissues [26, 27]. Moreover, because of their paramagnetic properties, solutions of chelated organic holmium and gadolinium complexes were used as intravenously directed gadolinium/holmium-based magnetic resonance imaging contrast agents in medical magnetic resonance imaging [26, 27].

The role of metal-ligand complex equilibria and the formation of bio-ligand complex is of therapeutic research interest [28-30]. To our knowledge, no work had been reported in using such mechanism in overcoming TQ bioavailability problem. TQ had shown to be safe in human beings. However, the usage of TQ in humans is inadequate owing to its chemical properties and poor membrane diffusion capability. The present study will have aimed at unfolding the possible use of the formed metal bio-ligand as a novel alternative in overcoming problems encountered with TQ in biological system and its therapeutic application. Recently, The stability constants of holmium(III) and gadolinium(III) metal ions-thymoquinone ligand complexation were considered wherein, the protonation constant of thymoquinone and the complex stability constants of each binary metal complex between both this metal ions and thymoquinone ligand (TQ) were determined and stated [31]. The hypothetical calculations of the global dissociation and complex stability constants of each metal complex classes in solutions were anticipated as 
the free energy change concomitant with the ligand protonation, dissociation, and metal ion-TQ complex process equilibria by means of density function theory (DFT) designs. The $\Delta \mathrm{G}$ values established that TQ form complex classes bind both metal ions and turns as chelating ligand. Moreover, the formation of diverse thymoquinone-holmium(III) and gadolinium(III) metal complex systems was established to be spontaneous process and exothermic interaction [31]. In this study, a structural characterization of the synthesized thymoquinone-holmium(III) and gadolinium(III) metal complexes was considered. Studying the antioxidant and antitumor relevance of holmium and gadolinium metal ion complexes of thymoquinone using cytotoxic and free radical scavenging assays was achieved.

\section{EXPERIMENTAL}

\section{Chemicals and reagents}

All the chemical substances, supplies, and organic solvents used during this research work were of analytical chemical grade and were used without additional purifications such as thymoquinone (Sigma-Aldrish, USA). This TQ material was assessed in triplicate by titration by a carbonate-free solution of standard $\mathrm{NaOH}$ chemical substance [31]. This test showed that the mass fraction purity of it was $(0.99 \pm 0.05)$. Holmium(III) nitrate pentahydrate $\left(\mathrm{Ho}\left(\mathrm{NO}_{3}\right)_{3} .5 \mathrm{H}_{2} \mathrm{O}\right.$; $99.99 \%$ trace metals basis), and gadolinium(III) nitrate hexahydrate $\left(\mathrm{Gd}\left(\mathrm{NO}_{3}\right)_{3} \cdot 6 \mathrm{H}_{2} \mathrm{O} ; 99.999 \%\right.$ trace metals basis) were used supplied from Sigma-Aldrich, USA. The organic solvents, methanol, ethanol, ether were of high purity.

\section{Synthesis of HoTQ and GdTQ metal complexes}

Holmium(III) and gadolinium(III) TQ complexes were created according to the next common procedure: An methanolic aliquots $(20 \mathrm{~mL})$ of each metal compound salts was added slowly in minor quantities to magnetically stirred methanolic aliquots $(20 \mathrm{~mL})$ of TQ till the reaction finished and refluxed at temperature of around $185^{\circ} \mathrm{C}$ for $6 \mathrm{~h}$. At that time, dehydration by pass in the subsequent reaction mixture in closet gases room, resulting in the isolation of solid precipitated complex yields. Then, they were filtered off, washed carefully using diethyl ether and ethanol solution mixture numerous times to eliminate any traces of unreacted starting ingredients and lastly dried in a vacuum desiccator over fused $\mathrm{CaCl}_{2}$ (final yield: $35-55 \%$ ). Digital Elico Conductivity Bridge meter (Model No. CM-180) was used to measure the molar conductance of the TQ bioligand and its holmium and gadolinium metal-TQ complexes in DMSO organic solutions with a concentration of about $1 \times 10^{-3} \mathrm{~mol}_{\text {. dm }}{ }^{-3}$ at room temperature by means of a dip-type conductivity cell tailored with a platinum electrode. Vibration infrared spectral (IR) studies of all prepared complexes were verified on a Shimadzu FT-IR 8000 spectrophotometer by means of $\mathrm{KBr}$ disc medium in the range $400-4000 \mathrm{~cm}^{-1}$ and the spectra were collected with a resolution of $2 \mathrm{~cm}^{-1}$ with 15 scans [32].

Cellular bioactivities of the synthesized metal complexes

\section{NF-kB luciferase assay using HSC-T6 C cells}

HSC-T6 Cells (around $7.5 \times 10^{4}$ cells/well) were sowed in 24-well micro plates with Fetal Bovine Serum (FBS) free medium at $37^{\circ} \mathrm{C}$ for one day earlier transfection. Transfection was achieved with transfection reagent FuGENE®6 transfection reagent (Promega, Madison, USA) rendering to manufacturer's conditions. NFkB-Luc reporter construct $(1.2 \mu \mathrm{g} / \mathrm{well})$ (Cayman Chemical, Michigan, USA) was added to the cells along with plasmid cytomegalovirus- $\beta$ galactosidase (CMV- $\beta$-gal, $0.22 \mu \mathrm{g} /$ well; Promega, Madison, USA) and transfection reagent (20 
$\mu \mathrm{L} / 24$-well plate). CMV- $\beta$-gal helped as an internal control to regularize the transfection efficacy. Subsequently, one day incubation, cell cultures were preserved with tested compounds (TQ bioligand, HoTQ, and GdTQ metal complexes) for half hour. Lipopolysaccharides (LPS) was then added to motivate NF- $\mathrm{KB}$ activity for $6 \mathrm{~h}$. Cell lysates were harvested with diluted reporter lysis $5 \mathrm{X}$ buffer (Promega, Madison, USA). 24-well plates were added reporter lysis buffer $(100 \mu \mathrm{L} /$ well $)$, and each $20 \mu \mathrm{L}$ cell lysate assorted with $100 \mu \mathrm{L}$ luciferin in 96-well

plates. Luminescence was identified by microplate lumimometer multilabel counter (TitertekBerthold, Pforzheim, Germany) [33, 34].

\section{Elastase release estimation}

Experimens were done using $\mathrm{MeO}-\mathrm{Suc}-\mathrm{Ala}-\mathrm{Ala}-\mathrm{Pro}-\mathrm{Val}-\mathrm{p}$-nitroanilide as elastase substrate. In brief, afterward supplementation with MeO-Suc-Ala-Ala-Pro-Val-p-nitroanilide $(100 \mu \mathrm{M})$, neutrophils $\left(6 \times 10^{5} / \mathrm{mL}\right)$ were equilibrated at $37^{\circ} \mathrm{C}$ for 2 min and incubated with TQ bioligand and its metal complexes for $10 \mathrm{~min}$. The cells were stimulated using formyl-1-methionyl-1leucyl-1-phenylalanine (FMLP) $(100 \mathrm{nM})$ and cytochalasin B (CB) $(0.5 \mu \mathrm{g} / \mathrm{mL})$. The variations in absorbance at $c a .405 \mathrm{~nm}$ ( $p$-nitrophenol) were instently measured to detect elastase release. The results are stated as a percentage of the original rate of elastase release in the formyl-1methionyl-1-leucyl-1-phenylalanine (FMLP)/cytochalasin B (CB)-activated, drug free control arrangements. To test whether the TQ bioligand and its metal complexes display an inhibitory ability to elastase activity, a direct elastase activity assay was done in a cell-free system. Neutrophils $\left(6 \times 10^{5} / \mathrm{mL}\right)$ were incubated for $20 \mathrm{~min}$ with formyl-1-methionyl-1-leucyl-1phenylalanine (FMLP) $(100 \mathrm{nM})$ and cytochalasin B (CB) $(2.5 \mu \mathrm{g} / \mathrm{mL})$ at $37^{\circ} \mathrm{C}$. After that, cells were centrifuged at $1,000 \mathrm{~g}$ for $7 \mathrm{~min}$ at $4{ }^{\circ} \mathrm{C}$ to collect the elastase from the supernatant. Then, the supernatant was equilibrated at $37^{\circ} \mathrm{C}$ for 5 min and incubated with or without TQ bioligand and its metal complexes for $10 \mathrm{~min}$. Then, the elastase substrate, MeO-Suc-Ala-Ala-Pro-Val- $p$ nitroanilide $(100 \mu \mathrm{M})$, was added to the reaction blends. Deviations in absorbance at $405 \mathrm{~nm}$ were incessantly detected for 10 min to evaluate the elastase activity [35-36].

\section{Measurement of superoxide anion $\left(\mathrm{O}_{2} \bullet-\right)$ generation}

The evaluation of $\mathrm{O}_{2}{ }^{--}$generation was done using the superoxide dismutase (SOD) inhabitable reduction of ferricytochrome $\mathrm{C}$. Briefly, once supplementation with $0.5 \mathrm{mg} / \mathrm{mlferricytochrome}$ $\mathrm{C}$ and $1 \mathrm{mM} \mathrm{Ca}^{2+}$, neutrophils $\left((4\right.$ or 10$\left.) \times 10^{5} \mu \mathrm{g} / \mathrm{mL}\right)$ were equilibrated at $37^{\circ} \mathrm{C}$ for about $2 \mathrm{~min}$ and incubated with TQ bioligand and its metal complexes for $10 \mathrm{~min}$. Cells were initiated with formyl-1-methionyl-1-leucyl-1-phenylalanine (FMLP) $(100 \mathrm{nM})$ for $10 \mathrm{~min}$. for $5 \mathrm{~min}$. When formyl-1-methionyl-1-leucyl-1-phenylalanine (FMLP) was used as a stimulant, cytochalasin $\mathrm{B}(\mathrm{CB})(1 \mu \mathrm{g} / \mathrm{mL})$ was incubated for $5 \mathrm{~min}$. Before activation by the peptide (FMLP/CB), superoxide anion $\left(\mathrm{O}_{2}{ }^{--}\right)$generation by isolated neutrophil fractionation was detected after the addition of $160 \mu \mathrm{M}$ NADPH to $800 \mu \mathrm{L}$ of relaxation buffer having $4 \times 10^{6}$ cell equivalents of membrane extract, $1.2 \times 10^{7}$ cell equivalents of cytosol, $2 \mu \mathrm{M}$ GTP- $\gamma-\mathrm{S}$, $0.5 \mathrm{mg} / \mathrm{mL}$ ferricytochrome $\mathrm{C}$, and $100 \mu \mathrm{M}$ sodium dodecyl sulfate. To make informal the association of NADPH oxidase components, all ingredients (without NADPH) were incubated at $37{ }^{\circ} \mathrm{C}$ for $5 \mathrm{~min}$ earlier the addition of NADPH. TQ bioligand and its metal complexes were incubated for $2 \mathrm{~min}$ before NADPH oxidase assemblage. Variations in absorbance with the reduction of ferricytochrome $\mathrm{C}$ at $550 \mathrm{~nm}$ were constantly detected. Calculations were done based on alterations in the reactions with and without superoxide dismutase (SOD, $100 \mathrm{U} / \mathrm{mL}$ ) divided by the extinction coefficient for the reduction of ferricytochromec $(\varepsilon=$ $2.11 \mathrm{mM}^{-1} \mathrm{~mm}^{-1}$ ) [37]. 


\section{DPPH radical scavenging activities}

Antioxidant influence of the tested compounds were established using the stable radical, 2,2diphenyl-1-picrylhydrazyl-hydrate (DPPH). All tested complex species were prepared in a mixture of neutral saline and DMSO. Around $50 \mu \mathrm{L}$ of each tested compound was retained in $1 \mathrm{~cm}$ cuvettes plus $2 \mathrm{~mL}$ methanolic mixtures of DPPH were added. At that time absorbance was detected. The reduction in absorbance was detected at $517 \mathrm{~nm}$ continually with data acquirement at $2 \mathrm{~s}$ intervals till the absorbance eased. The DPPH absorbance radical without the tested samples (control) was stately every 24 hours. Unusual maintenance was taken in consideration to diminish the loss of free radical activity of the DPPH radical standard solution as suggested. All experiments were done in triplicate. The percentage inhibition of the DPPH radical by gallate solution as standard antioxidant material and all tested compounds and their unique TQ bioligands was calculated based on the following equation: Percent inhibition $=$ $\left(\left[A_{\mathrm{C}(0)}-A_{\mathrm{C}(t)}\right] /\left[A_{\mathrm{C}(0)}\right]\right) \times 100$, where $A_{\mathrm{C}(0)}$ is the absorbance detected of the control at $t=0$ min and $A_{\mathrm{A}(t)}$ is the absorbance detected of the reaction solution mixture at $t=16 \min$ [38].

\section{Statistical analysis}

The investigational data were statistically evaluated by a parametric two tailed $t$ test, and calculated probability $\mathrm{p}$ values less than 0.05 were found to be a statistically significant. Once more than two investigational sets were examined, an ANOVA test by means of SPSS 17.0 statistical package was similarly used to estimate the statistical significance data.

\section{RESULTS AND DISCUSSION}

\section{Physical and chemical characterizations of synthesized complexes}

TQ bioligand, as well as its Ho(III), and Gd(III) complexes were exposed to elemental analysis. The elemental chemical and physical analytical data of the complexes showed 1:2 molar ratio (Ho/Gd : TQ). The synthesized complexes have melting points above $300{ }^{\circ} \mathrm{C}$. The molar conductivity values for the synthesized complexes $\left(1.0 \times 10^{-3} \mathrm{~mol} / \mathrm{mL}\right)$ were found to be between 32 and $51 \Omega^{-1} \mathrm{~cm}^{2} \mathrm{~mol}^{-1}$ indicating lightly electrolytic nature, and providing the degree of ionization of the complexes due to the existence of nitrate ions inside the coordination sphere which powerfully maintained with the elemental analysis data. The magnetic susceptibilities ( $\left.\mu_{\text {eff }}\right)$ of the Ho(III) and Gd(III)-TQ ligand complexes at $25{ }^{\circ} \mathrm{C}$ were found to be reliable with noticeable low-spin diamagnetism. The revelation of molecular structures of the prepared $\mathrm{Ho}(\mathrm{III})$ and Gd(III)-TQ ligand complexes were supported by IR spectroscopic technique. The prepared $\mathrm{Ho}$ (III) and Gd(III)-TQ ligand complexes were found to be stable at $25{ }^{\circ} \mathrm{C}$ with two diverse colors (Figure 2), wherein they are partially soluble in $\mathrm{D}_{2} \mathrm{O}$, while, they are soluble in DMSO and DMF organic solvents. The IR spectrum (Figure 1) showed a characteristic stretching band of the carbonyl group of a cyclohexadiene is observed at the wavenumber 1650 $\mathrm{cm}^{-1}$. The band presented at $2967 \mathrm{~cm}^{-1}$ relates to the $\mathrm{C}-\mathrm{H}$ stretching of aliphatic functional groups. The fragile wide band observed at a higher wavenumber (about $3040 \mathrm{~cm}^{-1}$ ) was assigned to the vinylic $\mathrm{C}-\mathrm{H}$ in the $\mathrm{C}=\mathrm{C}-\mathrm{H}$ groups. The $\mathrm{C}=\mathrm{C}$ stretching bands $\left(1640-1675 \mathrm{~cm}^{-1}\right)$ in $1,4-$ cyclohexadiene cannot be definitely recognized because the strong carboxylic stretching bands in thymoquinone is existing in this frequency range. Careful inspection of the IR spectra of free TQ bioligand and their the Ho(III) and Gd(III)-TQ ligand complexes was done in order to simplify the obligation of these bands in the free TQ bioligand and its holmium and gadolinium complexes (Figure 1). 


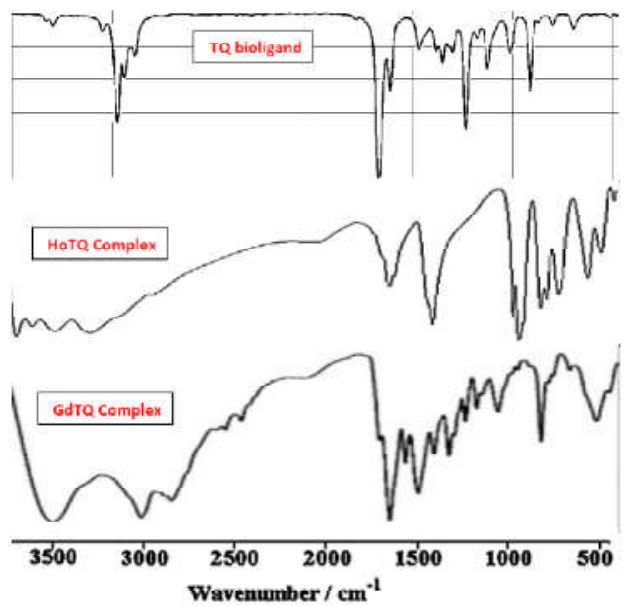

Figure 1. IR spectrum of TQ bioligand and its holmium (HoTQ), and gadolinium (GdTQ).

$N F-k B$ luciferase assay using HSC-T6 cells

The inhibitory effects of the tested TQ and its complexes were evaluated on inflammatory HSCT6. The most active compound was found to be TQ compound, followed by compounds Ho(TQ), then Gd(TQ) with inhibitory activity (\%) equals to 28.4, 14.2, and 13.2, respectively, against HSC-T6 (Table 1). Numerous experimental methods including immunoblot analysis, luciferase reporter gene assay, enzyme assay, over expression of target gene, and immunoprecipitation analysis confirmed that TQ targets interleukin-1 receptor-associated kinase 1 (IRAK1), which is complicated in the activation of together activator protein AP-1 and nuclear factor NF- $\mathrm{B}$ [39]. Furthermore, TQ instantaneously inhibited the induction of both NF$\kappa \mathrm{B}-$ and AP-1-driven luciferase activities [40]. The present results could suggest that several enzymes involved in the induction of the NF- $\mathrm{BB}$ and AP-1 pathways are targeted by TQ as well its Ho and Gd metal complexes.

Table 1. Inhibitory ratio of TQ bioligand and its metal complexes on inflammatory HSC-T6cells.

\begin{tabular}{|l|c|c|c|c|c|}
\hline Tested compound & $\begin{array}{c}\text { Silymarin } \\
(5 \mu \mathrm{g} / \mathrm{mL})\end{array}$ & $\begin{array}{c}\text { INF- } \alpha \\
(5 \mu \mathrm{g} / \mathrm{mL})\end{array}$ & $\begin{array}{c}\text { TQ } \\
(25 \mu \mathrm{g} / \mathrm{mL})\end{array}$ & $\begin{array}{c}\text { HoTQ } \\
(50 \mu \mathrm{g} / \mathrm{mL})\end{array}$ & $\begin{array}{c}\text { GdTQ } \\
(50 \mu \mathrm{g} / \mathrm{mL})\end{array}$ \\
\hline Light intensity & 39 & 109 & 81 & 59 & 43 \\
\hline Inhibitory activity (\%) & 87 & 0 & 28.4 & 14.2 & 13.2 \\
\hline
\end{tabular}

Elastase release estimation and detection of superoxide anion $\left(\mathrm{O}_{2} \bullet-\right)$ generation

Herein, the inhibitory effects of the TQ bioligand and its metal complexes were assessed on superoxide dismutase (SOD) and elastase release in human neutrophils and gadolinium(III)-TQ complex showed a moderate activity against the inhibition of superoxide anion generation (Table 2) against the inhibition of superoxide anion generation. TQ-holmium(III) complex showed a strong inhibitory effect against elastase release in stimulated human neutrophils. While, TQ and its gadolinium(III) complex showed a moderate inhibitory effect (Table 2) against elastase release in stimulated human neutrophils. Previous in vivo studies demonstrated that thymoquinone (TQ), a lipid soluble benzoquinone is a bioflavonoid managing inflammatory-associated diseases in which it reduces articular elastase and myeloperoxidase (MPO) activities, and suppresses the expression of pro-inflammatory cytokines [41]. 
Table 2. Inhibitory effects of TQ bioligand and its metal complexes on superoxide anion generation and elastase release in FMLP/CB induced human neutrophils.

\begin{tabular}{|l|c|c|c|c|}
\hline \multirow{2}{*}{$\begin{array}{l}\text { Tested } \\
\text { compounds }\end{array}$} & Superoxide anion & Elastase release & Superoxide anion & Elastase release \\
\cline { 2 - 5 } & \multicolumn{2}{|c|}{$\mathrm{IC}_{50}(\mu \mathrm{g} / \mathrm{mL})$} & \multicolumn{2}{c|}{ Inhibitory \% } \\
\hline TQ & $1.13 \pm 0.12$ & $26.67^{\mathrm{a}} \pm 0.57$ & $15.37^{\mathrm{a}} \pm 0.74$ & $12.36^{\mathrm{b}} \pm 0.57$ \\
\hline HoTQ & $1.64 \pm 0.11$ & $1.80 \pm 0.13$ & $79.56^{\mathrm{c}} \pm 2.10$ & $99.55^{\mathrm{c}} \pm 3.72$ \\
\hline GdTQ & $16.23^{\mathrm{b}} \pm 0.34$ & $105.84^{\mathrm{c}} \pm 3.15$ & $20.09^{\mathrm{b}} \pm 1.13$ & $6.32 \pm 0.78$ \\
\hline
\end{tabular}

${ }^{a}$ Percentage of inhibition (Inhibitory \%) at $10 \mathrm{mg} / \mathrm{mL}$ concentration. Results are presented as mean \pm S.E.M. (n $=$ 34). ${ }^{\mathrm{a}} p<0.05,{ }^{\mathrm{b}} p<0.01,{ }^{\mathrm{c}} p<0.001$ compared with the control value (DMSO).

\section{DPPH free-radical scavenging test}

Antioxidant activity is unique of the significant standard tests in pharmaceutical industry to inspect the potency of a tested compound to inhibit the creation of free radical. 2,2-Diphenyl-1picrylhydrazyl (DPPH) is a general "steady free-radical" for antioxidant test. The vigorous DPPH radical has a robust absorption band at $517 \mathrm{~nm}$ with a violet color in solution. The neutralization of DPPH by each antioxidant tested compound gives band at $517 \mathrm{~nm}$ to decline and each solution color develops pale yellow color. From the results obtained for the tested compounds, it was found all TQ complexes showed an antioxidant activity (Figure 2). The cytochrome $\mathrm{C}$ system turned out to be inappropriate for the assessment of the antioxidant activity of thymoquinone. Thymoquinone concentration-dependently (250-2000 ppm) stimulated the NADH oxidation of submitochondrial particles in which he thymoquinonestimulated NADH oxidation was sensitive to inhibitors of the mitochondrial electron transfer [42]. Generally, thymoquinone possesses a moderate antioxidant activity assuming that the mitochondrial respiratory chain is significant for the antioxidant properties of thymoquinone in the cell in contrast to tis Ho and Gd metal complexes.

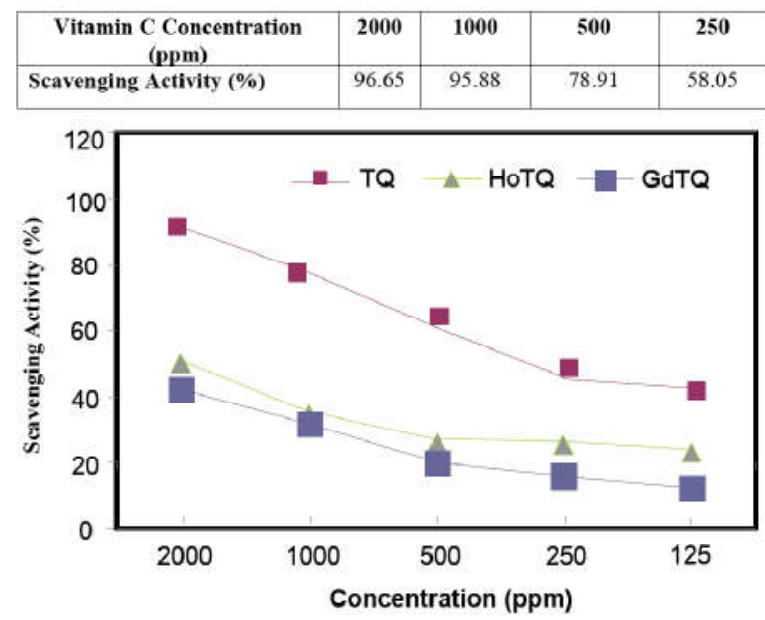

Figure 2. DPPH scavenging activity of TQ bioligand and its metal complexes comparing with vitamin C. 


\section{CONCLUSION}

The present study aimed at unfolding the possible usage of the formed bio-ligand metal complexes as a novel alternative in overcoming problems encountered with thymoquinone in biological system and its therapeutic application. Thymoquinone had shown to be safe in human beings. However, the use of thymoquinone in humans is limited due to its chemical properties and poor membrane penetration capacity. Thymoquinone is chemically hydrophobic, which causes its poor solubility, and thus bioavailability. Many experimental studies have been conducted to overcome the pharmacokinetic problems of thymoquinone, its adverse effect. A highly promising and innovative approach to deal with the bioavailability issue and to achieve even more diverse potential health benefits is the use of metal thymoquinone complex, forming a complex formation. Yet, discovering other mechanism to increase the bioavailability of thymoquinone particularly chemical modelling may show as a novel method. The role of metalligand complex equilibrium and the formation of bio-ligand complex are of therapeutic interest in this study.

\section{ACKNOWLEDGMENTS}

The authors extend their appreciation to the Deanship of Scientific Research at King Khalid University for supporting this work through research groups program under grant number R.G.P 2/106/41.

\section{REFERENCES}

1. Grieve, D.J.; Davidson, S.M. New insights into cardiotoxicity caused by chemotherapeutic agents. Br. J. Pharmacol. 2017, 174, 3675-3676.

2. Copur, M.S.; Ramaekers, R.; Crockett, D. Gauchan, D. Miscellaneous Chemotherapeutic Agents in DeVita Hellman, Rosenberg's Cancer, Principles and Practice of Oncology. Wolters Kluwer Health Pharma Solutions (Europe) Ltd.; 2008; p. 338-347.

3. Negi, P.; Rathore, C.; Sharma, G.; Singh, B. Katare, O.P. Thymoquinone a potential therapeutic molecule from the plant Nigella sativa: Role of colloidal carriers in its effective delivery. Recent Pat. Drug Deliv. Formul. 2018, 12, 3-22.

4. Imran, M.; Rauf, A.; Khan, I.A.; Shahbaz, M.; Qaisrani, T.B.; Fatmawati, S.; Abu-Izneid, T.; Imran, A.; Rahman, K.U. Gondal, T.A. Thymoquinone: A novel strategy to combat cancer. Biomed. Pharmacother. 2018, 106, 390-402.

5. Mohammad A.M.R.; Mozafari, M.R. Enhanced efficacy and bioavailability of thymoquinone using nanoliposomal dosage form. J. Drug Deliv. Sci. Technol. 2018, 47, 445-453.

6. Ballout, F.; Habli, Z.; Rahal, O.N.; Fatfat, M. Gali-Muhtasib, H. Thymoquinone-based nanotechnology for cancer therapy: Promises and challenges. Drug Discov. Today, 2018, 23, 1089-1098.

7. Sanati, A.R.; Farkhondeh, T. Samarghandian, S. Antidotal effects of thymoquinone against neurotoxic agents. Interdiscip. Toxicol. 2018, 11, 122-128.

8. Khan, M.A. Younus, H. Thymoquinone shows the diverse therapeutic actions by modulating multiple cell signaling pathways: Single drug for multiple targets. Curr. Pharm. Biotechno. 2018, 19, 934-945.

9. Noorbakhsh, M.-F.; Hayati, F.; Samarghandian, S.; Shaterzadeh-Yazdi, H. Farkhondeh, T. An overview of hepatoprotective effects of thymoquinone. Recent. Pat. Food Nutr. Agric. 2018, 9, 14-22.

10. Shaterzadeh-Yazdi, H.; Noorbakhsh, M.-F.; Hayati, F.; Samarghandian, S. Farkhondeh, T. Immunomodulatory and anti-inflammatory effects of thymoquinone. Cardiovasc. Hematol. Disord. Drug Targets 2018, 18, 52-60. 
11. Tavakkoli, A.; Mahdian, V.; Razavi, B.M. Hosseinzadeh, H. Review on clinical trials of black seed (Nigella sativa) and its active constituent, thymoquinone. J. Pharmacopunct. 2017, 20, 179-193.

12. Khan, M.A.; Tania, M.; Fu, S. Fu, J. Thymoquinone, as an anticancer molecule: From basic research to clinical investigation. Oncotarget, 2017, 8, 51907-51919.

13. Darakhshan, S.; Bidmeshki Pour, A.; Hosseinzadeh Colagar, A. Sisakhtnezhad, S. Thymoquinone and its therapeutic potentials. Pharmacol. Res. 2015, 95-96, 138-158.

14. Schneider-Stock, R.; Fakhoury, I.H.; Zaki, A.M.; Elbaba, C.O. Gali-Muhtasib, H.U. Thymoquinone: Fifty years of success in the battle against cancer models. Drug Discov. Today 2013, 19, 18-30.

15. AbuKhader, M.M. Thymoquinone: A promising antidiabetic agent. Int. J. Diabetes Dev. Ctries. 2012, 32, 65-68.

16. Banerjee, S.; Padhye, S.; Azmi, A.; Wang, Z.; Philip, P.A.; Kucuk, O.; Sarkar, F.H. Mohammad, R.M. Review on molecular and therapeutic potential of thymoquinone in cancer. Nutr. Cancer 2010, 62, 938-946.

17. Chowdhury, F.A.; Hossain, M.K.; Mostofa, A.G.M.; Akbor, M.M. Bin Sayeed, M.S. Therapeutic potential of thymoquinone in glioblastoma treatment: Targeting major gliomagenesis signaling pathways. BioMed. Res. Int. 2018, 2018, DOI: $10.1155 / 2018 / 4010629$.

18. Barkat, M.A.; Harshita, Ahmad, J.; Khan, M.A.; Beg, S. Ahmad, F.J. Insights into the targeting potential of thymoquinone for therapeutic intervention against triple-negative breast cancer. Curr. Drug Targets 2018, 19, 70-80.

19. Mostofa, A.G.M.; Hossain, M.K.; Basak, D. Sayeed, M.S.B. Thymoquinone as a potential adjuvant therapy for cancer treatment: Evidence from preclinical studies. Front. Pharmacol. 2017, 8, DOI: 10.3389/fphar.2017.00295.

20. Elmaci, I.; Altinoz, M.A. Thymoquinone: An edible redox-active quinone for the pharmacotherapy of neurodegenerative conditions and glial brain tumors. Biomed. Pharmacother. 2016, 83, 635-640.

21. Abukhader, M. Thymoquinone in the clinical treatment of cancer: Fact or fiction. Pharmacogn. Rev. 2013, 7, 117-120.

22. Tekbas, A.; Huebner, J.; Settmacher, U. Dahmen, U. Plants and surgery: The protective effects of thymoquinone on hepatic injury-a systematic review of in vivo studies. Int. J. Mol. Sci. 2018, 19, 1085-1110.

23. Iqbal, S.; Javeed, A.; Sattar, A.; Tanvir, R. Pharmacokinetics of thymoquinone in layer chickens following oral and intravenous administration. J. Vet. Pharmacol. Therap. 2019, 4, 707-712.

24. Talebi, M.; Talebi, M.; Farkhondeh, T.; Samarghandian, S. Biological and therapeutic activities ofthymoquinone: Focus on the Nrf2 signaling pathway. Phytother. Res. 2020, 115 .

25. Alkharfy, K.M.; Ahmad, A.; Khan, R.M.; Al-Shagha, W.M. Pharmacokinetic plasma behaviors of intravenous and oral bio-availability of thymoquinone in a rabbit model. Eur. $J$. Drug Metab. Pharmacokinet. 2015, 40, 319-323.

26. Caravan, P.; Ellison, J.J.; McMurry, T.J.; Lauffer, R.B. Gadolinium(III) chelates as MRI contrast agents: Structure, dynamics, and applications. Chem. Rev. 1999, 99, 2293-2352.

27. Wollin, T.A.; Denstedt, J.D. The holmium laser in urology. J. Clin. Laser Med. Surg. 1998, 16, 13-20.

28. Fazary, A.E. Metal complexes of salicylhydroxamic acid and 1,10-phen-anthroline; equilibrium and antimicrobial activity studies. Bull. Chem. Soc. Ehiop. 2014, 28, 393-402.

29. Awwad, N.S.; Ibrahium, H.A.; Shati, A.A.; Alfaifi M.Y.; Ju, Y.H.; Fazary, A.E. Nicotine metal complexes: Synthesis, characterization and bioactivities of some main group and some transition metals. Bull. Chem. Soc. Ehiop. 2020, 34, 501-521. 
30. Fazary, A.E.; Ju, Y-H.; Bani-Fwaz, M.Z.; Alshihri, A.S.; Alfaifi, M.Y.; Saleh, K.A.; Elbehairi, S.E.I.; Fawy, K.F. Abd-Rabboh, H.S.M. Platinum and vanadate bioactive complexes of glycoside narin:in and phenolates. Open Chem. 2017, 15, 189-199.

31. Fazary, A.E.; Ibrahium, H. A.; Youssef, M.A.; Awwad, N.S.; Abd-Rabboh, H.S.M. Solution equilibria of holmium(III) and gadolinium(III) complexes of thymoquinone. J. Solution Chem. 2019, 48, 1716-1729.

32. Liu, Y.-W. Huang, Y.-T. Inhibitory effect of Tanshinone IIA on rat hepatic stellate cells. PLoSONE, 2014, e1032299 (7), 1-10.

33. Hwang, T.-L.; Hung, C.-H.; Hsu, C.-Y.; Huang, Y.-T.; Tsai, Y.-C. Hsieh, P.-W. Design and synthesis of tryptophan containing dipeptide derivatives as formyl peptide receptor 1 antagonist. Org. Biomol. Chem. 2013, 11, 3742-3755.

34. Hwang, T.-L.; Wang, W.-H.; Wang, T.-Y.; Yu, H.-P. Hsieh, P.-W. Synthesis and pharmacological characterization of 2-aminobenzaldehyde oxime analogs as dual inhibitors of neutrophil elastase and proteinase 3. Bioorg. Med. Chem. 2015, 23, 1123-1134.

35. Hwang, T.-L.; Yeh, S.-H.; Leu, Y.-L.; Chern, C.-Y. Hsu, H.-C. Inhibition of superoxide anion and elastase release in human neutrophils by 3 '-isopropoxychalcone via a cAMPdependent pathway. Br. J. Pharmacol. 2006, 148, 78-87.

36. Chung, C.-Y.; Hwang, T.-L.; Kuo, L.-M.; Kuo, W.-L.; Cheng, M.-J.; Wu, Y.-H. Sung, P.-J.; Chung, M.-I.; Chen, J.-J. New benzo[c]phenanthridine and benzenoid derivatives, and other constituents from Zanthoxylum ailanthoides: Effects on neutrophil pro-inflammatory responses. Int. J. Mol. Sci. 2013, 14, 22395-22408.

37. Cheng, H.-H.; Cheng, Y.-B.; Hwang, T.-L.; Kuo, Y.-H.; Chen, C.-H. Shen, Y.-C. Randainins A-D, based on unique diterpenoid architectures, from Callicarpa randaiensis. $J$. Nat. Prod. 2015, 78, 1823-1828.

38. Suzen, S.; Gurkok, G. Coban, T. Novel N-acyl dehydroalanine derivatives as antioxidants: Studies on rat liver lipid peroxidation levels and DPPH free radical scavenging activity. $J$. Enzyme Inhib. Med. Chem. 2006, 21, 179-185.

39. Hossen, M.; Yang, W.; Kim, D.; Aravinthan, A.; Kim, J-H.; Cho, J. Thymoquinone: An IRAK1 inhibitor with in vivo and in vitro anti-inflammatory activities. Sci. Rep. 2017, 7(42995), 1-12.

40. Seya, T.; Oshiumi, H.; Sasai, M.; Akazawa, T.; Matsumoto, M. TICAM-1 and TICAM-2: toll-like receptor adapters that participate in induction of type 1 interferons. Int. J. Biochem. Cell Biol. 2005, 37, 524-529.

41. Umar, S.; Zargan, J.; Umar, K.; Ahmad, S.; Katiyar, C.K.; Khan, H.A. Modulation of the oxidative stress and inflammatory cytokine response by thymoquinone in the collagen induced arthritis in Wistar rats. Chem. Biol. Interact. 2012, 197, 40-46.

42. Staniek, K.; Gille, L. Is thymoquinone an antioxidant? BMC Pharmacol. 2010, 10(A9), 1-1. 